\title{
ORIGIN OF ELEMENTS \\ IN THE SOLAR SYSTEM
}




\title{
ORIGIN OF ELEMENTS IN THE SOLAR SYSTEM IMPLICATIONS OF POST-1957 OBSERVATIONS
}

\author{
Edited by \\ O. Manuel \\ University of Missouri \\ Rolla, Missouri
}

Proceedings of the International Symposium Organized by Glenn T. Seaborg and Oliver K. Manuel

KLUWER ACADEMIC PUBLISHERS

NEW YORK, BOSTON, DORDRECHT, LONDON, MOSCOW 
eBook ISBN: $\quad 0-306-46927-8$

Print ISBN: $\quad 0-306-46562-0$

(C)2002 Kluwer Academic Publishers

New York, Boston, Dordrecht, London, Moscow

Print @2000 Kluwer Academic / Plenum Publishers

New York

All rights reserved

No part of this eBook may be reproduced or transmitted in any form or by any means, electronic, mechanical, recording, or otherwise, without written consent from the Publisher

Created in the United States of America

Visit Kluwer Online at:

http://kluweronline.com

and Kluwer's eBookstore at:

http://ebooks.kluweronline.com 


\section{Contributors}

Ahmad, Irshad, Physics, Argonne National Laboratory, Argonne, IL, USA Alexander, E. Calvin, Jr., Geology and Geophysics, University of Minnesota, Minneapolis, MN, USA

Anders, Edward (retired), The Enrico Fermi Institute, University of Chicago, Chicago, IL, USA

Anthony, Don W., National Superconducting Cyclotron Laboratory, Michigan State University, East Lansing, MI, USA

Arlandini, Claudio, Forschungszenturm Karlsruhe Institut für Kernphysik III, Karlsruhe, GERMANY

Armbruster, Peter, GSI (Gesellschaft für Schwerionforschung), Darmstadt GERMANY

Ballad, Robert V., Knolls Atomic Power Laboratory, Schenectady, NY, USA*

Bateman, Nick, Simon Frasier University, Burnaby, B. C., CANADA

Becker, Victor J., Diatide, Inc., Londonderry, NH, USA*

Bernas, Monique, Institut de Physique Nuclèaire d'Orsay, Orsay, FRANCE

Bildsten, Lars, Physics and Astronomy, University of California, Berkeley, CA, USA

Brown, Wilbur K. (retired), Los Alamos National Laboratory, Los Alamos, NM, USA

Browne, Edgardo, Lawrence Berkeley National Laboratory, Berkeley, CA, USA

Burbidge, Geoffrey R., Center for Astrophysics and Space Sciences, University of California, San Diego, CA, USA

Casey, William H., L.A.W.R. and Geology Departments, University of California, Davis, CA, USA* 
Chevalier, Roger A., Astronomy and Astrophysics, University of Virginia, Charlottesville, VA, USA

Chiou, George K. Y., IBM/FD Analytical Laboratory, IBM Corporation, San Jose, CA, USA*

Cumming, A., Physics and Astronomy, University of California, Berkeley, CA, USA

D'Auria, John, The DRAGON Collaboration, Simon Fraser University, Burnaby, B.C., CANADA

De Laeter, John R., Applied Physics, Curtain University, Perth, WESTERN AUSTRALIA

Downing, R. Greg, R. G. D. Research, Inc., Niskayuna, NY, USA*

Ebihara, Mitsuru, Chemistry, Tokyo Metropolitan University, Tokyo, JAPAN

Fang, Jiafu, Pennzoil Quaker State Company, Technology Division, The Woodlands, TX, USA*

Fowler, Malcolm M., Nuclear and Radiochemistry, Los Alamos National Laboratory, Los Alamos, NM, USA

Frank, Adam, Physics and Astronomy, University of Rochester, Rochester, NY, USA

Ganapathy, R., Bethlehem, PA, USA*

Ghiorso, Albert, Lawrence Berkeley National Laboratory, University of California, Berkeley, CA, USA

Giesen, U., Physics, University of Notre Dame, Notre Dame, IN, USA

Goswami, Jitendra Nath, Physical Research Laboratory, Ahmedabad, INDIA

Greene, John P., Physics, Argonne National Laboratory, Argonne, IL, USA

Gregorich, Ken, Lawrence Berkeley National Laboratory, University of California, Berkeley, CA, USA

Grevesse, Nicolas, Institut d'Astrophysique, Université de Liège, OugréeLiège, BELGIUM

Guzik, Joyce Ann, Applied Theoretical and Computational Physics Division, Los Alamos National Laboratory, Los Alamos, NM, USA

Haight, Robert C., Los Alamos Neutron Science Center (LANSCE), Los Alamos, NM, USA

Hashimoto, Yuji, Chemistry, Kanazawa University, Kanazawa, JAPAN

Hoffman, Robert D., Lawrence Livermore National Laboratory, Livermore, CA, USA

Huss, Gary R., Geological and Planetary Sciences, California Institute of Technology, Pasadena, CA, USA

Hwaung, Golden, Electrical and Computing Engineering, Lousiana State University, Baton Rouge, LA, USA

Johnson, Robert, Chemistry, University of Missouri, Rolla, MO, USA* 
Käppeler, Franz, Forschungszentrum Karlsruhe Institut für Kernphysik III, Karlsruhe, GERMANY

Koehler, Paul E., Oak Ridge National Laboratory, Oak Ridge, TN, USA

Kohman, Truman (retired) Chemistry, Carnegie-Mellon University, Pittsburg, PA, USA*

Kratz, Karl L., Institut für Kernchemie, Universität Mainz, Mainz, GERMANY

Kuroda, Paul K. (retired), Chemistry, University of Arkansas, Fayetteville, AR, USA

Kutschera, Walter, Institut für Radiumforschung und Kernphysik, Universität Wien, Vienna, AUSTRIA

Lal, Devendra, Geosciences, Scripps Institution of Oceanography, La Jolla, CA, USA

Larimer, John W., Geology, Arizona State University, Tempe, AZ, USA*

Lee, Jauh T., Advanced Separation Technologies, Inc., Whippany, NJ, USA*

Lewis, Roy S., The Enrico Fermi Institute, University of Chicago, Chicago, IL, USA

Lhersonneau, Gerard, Physics, University of Jyvaskyla, Jyvaskyla, FINLAND

Li, Bin, Lunar and Planetary Laboratory, University of Arizona, Tucson, AZ, USA*

Lietz, Cara, Chemical Engineering, University of Missouri, Rolla, MO, USA

Lofy, P. A., National Superconducting Cyclotron Laboratory, Michigan State University, East Lansing, MI, USA

Loss, Robert D., Applied Physics, Curtin University, Perth, WESTERN AUSTRALIA

Lu, Qi, Chemistry, University of Tokyo, Tokyo, JAPAN

Lugmair, Günther W., Geosciences, Scripps Institute of Oceanography and Max-Planck Institut für Chemie, Mainz, GERMANY

Maas, Roland, Geology, Latrobe University, Victoria, AUSTRALIA

Mantica, P. F., National Superconducting Cyclotron Laboratory, Michigan State University, East Lansing, MI, USA

Manuel, Oliver K., Chemistry, University of Missouri, Rolla, MO, USA

Masuda, Akimasa (retired), Chemistry, University of Tokyo, Tokyo, JAPAN

Miller, Geoffrey G., Los Alamos National Laboratory, Los Alamos, NM, USA

Möller, Peter, Theoretical Division, Los Alamos National Laboratory, Los Alamos, NM, USA

Morrissey, David J., National Superconducting Cyclotron Laboratory, Michigan State University, East Lansing, MI, USA 
Morss, Lester, Chemistry Division, Argonne National Laboratory, Argonne, IL, USA*

Myers, William A., Chemical Engineering, University of Arkansas, Fayetteville, AR, USA

Nakanishi, Takashi, Chemistry, Kanazawa University, Kanazawa, JAPAN

Neuforge, Corinne, Los Alamos National Laboratory, Los Alamos, NM, USA

Ninov, V., Lawrence Berkeley National Laboratory, Berkeley, CA, USA

Nolte, Adam, Chemical Engineering, University of Missouri, Rolla, MO, USA

Norman, Eric B., Lawrence Berkeley National Laboratory, University of California, Berkeley, CA, USA

Ott, Ulrich, Max-Planck Institut für Chemie, Mainz, GERMANY

Oura, Y., Chemistry, Tokyo Metropolitan University, Tokyo, JAPAN

Ozaki, Hiromasa, Chemistry, Tokyo Metropolitan University, Tokyo, JAPAN

Palmer, Phillip D., Los Alamos National Laboratory, Los Alamos, NM, USA

Paul, Michael, Racah Institiute of Physics, Hebrew University, Jerusalem, ISRAEL

Pfeiffer, Bernd, Institut für Kernchemie, Universität Mainz, Mainz, GERMANY

Pilcher, Carl, NASA Headquarters, Washington, DC, USA*

Prisciandaro, Joann I., Cyclotron Laboratory, Michigan State University, East Lansing, MI, USA

Ramadurai, Souriraja, TIFR/Astrophysics Group, Colaba, Mumbai, INDIA

Rauscher, Thomas, Physics, University of Basel, Basel, SWITZERLAND

Rosman, K. J. R., Applied Physics, Curtin University, Perth, WESTERN AUSTRALIA

Rouse, Carl A. (retired), GA Technologies, Inc., San Diego, CA, USA

Rowe, Marvin W., Chemistry, Texas A\&M University, College Station, TX, USA

Rundberg, Robert S., Nuclear and Radiochemistry, Los Alamos National Laboratory, Los Alamos, NM, USA

Sakamoto, Koh, Chemistry, Kanazawa University, Kanazawa, JAPAN

Sauval, A. Jacques, Observatoire Royal de Belgique, Bruxelles, BELGIUM

Schatz, Hendrik, GSI (Gesellschaft für Schwerionenforschung), Darmstadt, GERMANY

Seabury, Edward H., Los Alamos Neutron Science Center (LANSCE), Los Alamos, NM, USA

Shimamura, Tadashi, School of Allied Health Sciences, Kitasato University, Sagamihara, Kanagawa, JAPAN 
Shinotsuka, Kazunori, National Institute for Fusion Science, Gifu, JAPAN

Steiner, M., Cyclotron Laboratory, Michigan State University, East Lansing, MI, USA

Sorlin, Olivier, Institut de Physique Nucleaire, Orsay Cedex, FRANCE

Tanaka, T., Earth and Planetary Sciences, Nagoya University, Nagoya, JAPAN

Tanimizu, Masaharu, Earth and Planetary Sciences, Nagoya University, Nagoya, JAPAN

Thielemann, Friedrich-Karl, Department für Physik und Astronomie, University of Basel, Basel, SWITZERLAND

Trimble, Virginia, Astronomy and Astrophysics, University of Maryland, College Park, MD, USA

Ullman, John L., LANSCE-3, Los Alamos National Laboratory, Los Alamos, NM, USA

Vahia, Mayank N., Astronomy and Astrophysics, Tata Institute of Fundamental Research, Mumbai, INDIA

Viola, Vic, Chemistry, University of Indiana, Bloomington, IN, USA

Voss, Fritz, Forschungszentrum Karlsruhe Institut für Kernphysik III, Karlsruhe, GERMANY

Ward, Thomas E. (Consultant), U.S. Department of Energy, Washington, DC, USA

Wiescher, M., Physics, University of Notre Dame, Notre Dame, IN, USA

Wilhelmy, Jerry B., Los Alamos National Laboratory, Los Alamos, NM, USA

Windler, Ken, Chemistry, University of Illinois, Urbana-Champagne, IL, USA

Wisshak, Klaus, Forschungszentrum Karlsruhe Institut für Kernphysik III, Karlsruhe, GERMANY

Woolsey, Stanford E., Lawrence Livermore National Laboratory, University of California, Santa Cruz, CA, USA

Xie, Yixiang, Electronic Materials Applied Research Center, University of Missouri, Rolla, MO, USA*

*Participant or author of paper presented at the symposium but not published in these proceedings. 


\title{
Preface and Dedication
}

\author{
"Satyam eva jayate nanritan" \\ "Truth is victorious, never untruth" \\ Mundaka Upanishad, III.1.6
}

"From where did all this come?" has been one of the fundamental questions since the dawning of civilization. These proceedings record the diversity of opinions on this subject as the 20th century draws to an end.

When the landmark papers by Burbidge, Burbidge, Fowler and Hoyle $\left(\mathrm{B}_{2} \mathrm{FH}\right)$ and Cameron on stellar nucleosynthesis appeared in 1957, the periodic table ended at element \#101, the latest discovery of Ghiorso and coworkers. Experiments described here tell of the production of heavier elements in the intervening years, in labs at Dubna, GSI-Darmstadt and Berkeley. Element \#114 was reported when this symposium was in the planning stages, and the Berkeley group reported the discovery of elements \#118, \#116 and \#114 at the symposium. These proceedings also contain exciting new information from laboratory studies on the life-times and crosssections of nuclides under extreme, stellar-like conditions, often far from the region of nuclear stability.

More stable nuclides are more abundantly formed in laboratory studies. "Fine-structure" elemental abundance peaks also occur in nature at multiples of the ${ }^{4} \mathrm{He}$ nuclide, at iron ( $\left.\mathrm{Fe}\right)$, and at closed shells of nucleons. One issue debated here is whether this relationship between abundance and nuclear stability holds for the overall composition of the solar system. The answer depends if the solar interior $(\approx 99.8 \%$ of the mass of the solar system) is mostly ' $\mathrm{H}$, the stable nuclide with the highest mass per nucleon, or ${ }^{56} \mathrm{Fe}$, the nuclide with the lowest mass per nucleon. Several papers here suggest that 
seismology, neutrinos and isotopic ratios from the sun may soon resolve differences of opinion on the sun's internal structure and composition.

Observations of the skies, particularly with the Hubble Space Telescope, have given us new details on the birth and death of stars and of planetary systems. The discovery of pulsar planets clearly illustrates one unexpected end product of a supernova explosion. The explosion of a nearby supernova, SN1987A, provides new details about the nuclear reactions that occur under these extreme conditions and the dynamics and composition of material ejected by supernovae. In these proceedings it is shown that the decay of doubly magic ${ }^{56} \mathrm{Ni}$, rather than a heavy element like ${ }^{254} \mathrm{Cf}$, dominated the light curve of SN1987A. Since ${ }^{56} \mathrm{Ni}$ is the parent of the most abundant iron isotope, ${ }^{56} \mathrm{Fe}$, SN1987A has clearly demonstrated one way to make isotopic anomalies, short-lived nuclides, and a region rich in iron.

As the 20th century was ending, Professor Glenn Seaborg and I sought to bring together a blend of experimentalists and theorists from astronomy, chemistry, geology, physics and related disciplines to summarize the current understanding of the origin of elements that comprise the solar system.

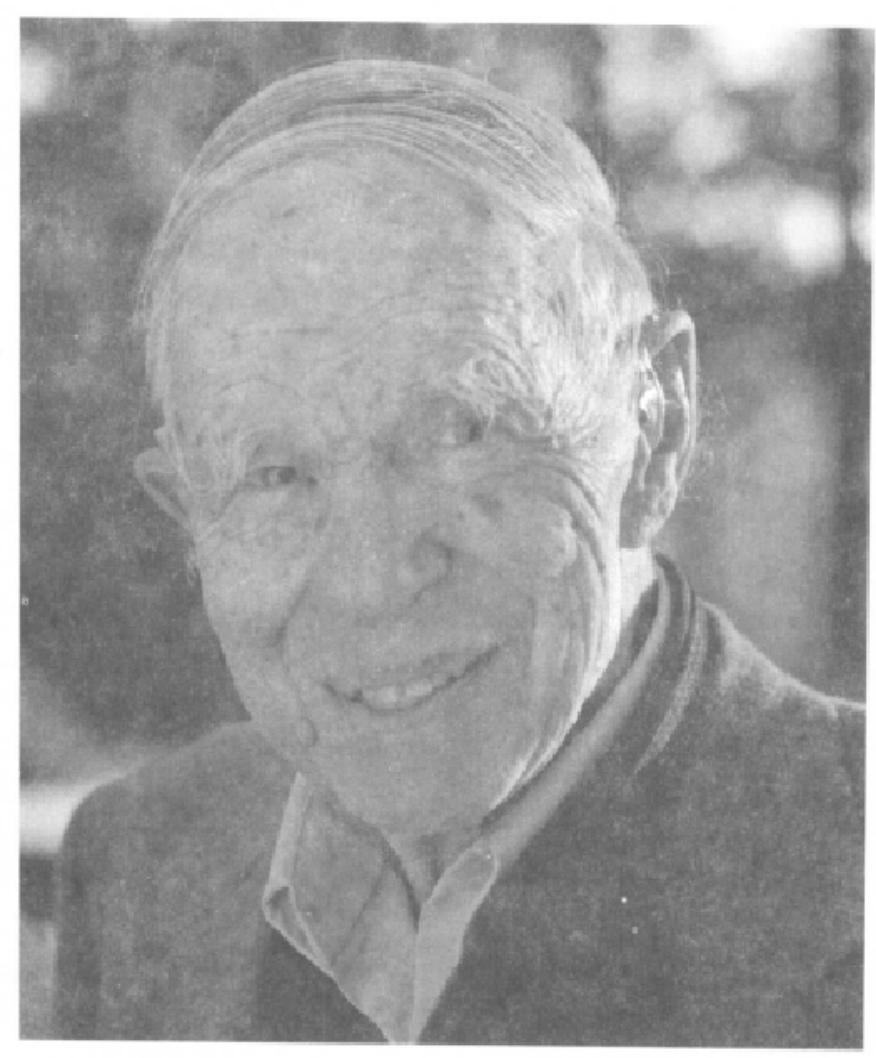

Glenn Seaborg (Courtesy of Piermaria J. Oddone) 
This volume is dedicated to the memory of the late Professor Glenn T. Seaborg, who agreed in April of 1998 to give the keynote address and to cochair this symposium. Drs. Al Ghiorso and Ken Gregorich knew Glenn much better than I did. Their papers in this volume give great insight into the genius of this man and his influence on science, education, and government policies in the 20th century.

Although I hardly knew Glenn personally, his influence on my scientific career has been tremendous since April of 1976 when one of his former students, Vic Viola, attended the annual AGU meeting in Washington, D.C. There, two students of Professor Paul K. Kuroda were trying to convince the audience that isotopically "strange" xenon in meteorites came from nuclear reactions in the supernova $(\mathrm{SN})$ that made our elements, not from later fission of a superheavy element (SHE) within meteorite grains. Knowing that his mentor would want to hear the debate on SHE vs SN, Vic invited me to speak at a San Francisco ACS symposium on the origin of the elements in the fall of 1976. That was where I first met Professor Seaborg.

The next year, Glenn asked me to comment on SHE vs SN at the Robert Welch Conference on Cosmochemistry. Over the next 20 years, "strange" isotopic ratios were found in several elements of meteorites and great advances were made in producing SHEs in the laboratory (e.g., the first three papers in this volume). Glenn was eager to co-chair the 1999 ACS symposium where these observations would be discussed and a cross section of opinions at the end of the 20th century recorded in these proceedings.

Glenn personally invited many distinguished speakers but Death, the greatest teacher of all, intervened shortly before the program was completed and SHEs \# 118, 116, ... were discovered in Glenn's lab (Gregorich, this volume). Death itself teaches that, "The all-knowing Selfwas never born, nor will it die. Beyond cause and effect, this Self is eternal and immutable. When the body dies, the Self does not die." (Katha Upanishad, I.2.18).

Following this tragedy, Professor Geoffrey Burbidge (this volume) graciously agreed to give the keynote address. Accompanied by his lovely wife, Margaret, these two towering figures firmly linked the discussion to the period when stellar nucleosynthesis was conceived, in the middle of the 20th century, to the time of the symposium, as the 20th century was drawing to an end.

In keeping with Glenn's spirit, we adopted the following motto for the symposium: "Satyam eva jayate nanritan" (Mundaka Upanishad, III. 1.6). "Truth is victorious, never untruth."

O. Manuel 


\section{Acknowledgements}

Special thanks go to

- Glenn T. Seaborg for planning and organizing the meeting and for agreeing to co-chair the symposium.

- Karl-Ludwig Kratz, Mitsuru Ebihara, and Mayank Vahia served with Glenn as members of the Scientific Program Committee.

- Doris Demerjian, Al Ghiorso, and Ken Gregorich - close friends and associates of Glenn Seaborg - kept the forward momentum going during the difficult period of his illness and death and helped us bring the symposium to a successful completion.

- Peter Armbruster chaired the special session of the symposium in memory of Glenn Seaborg

- Al Ghiorso prepared the video about Glenn that was the highlight of the special session in his memory.

- Ken Gregorich told us about the culmination of Seaborg's career with the discovery of elements 118,116 and 114 in his laboratory.

- Geoffrey Burbidge presented an eloquent and memorable keynote address on the synthesis of elements.

- Margaret Burbidge and Truman Kohman were present to share memories of pioneering work on the origin of the elements.

- Carl Pilcher, Jack Larimer, Bin Li, and Greg Downing gave important papers at the meeting but were unable to submit papers for publication in this proceedings.

- Virginia Trimble and Akimasa Masuda were unable to attend the meeting but contributed papers to this proceedings. 
- Kittie Robertson and Sherry Adams handled daily planning and arranged for housing and the reception at the symposium.

- Phyllis Johnson typed and organized the proceedings. She was assisted by Patty Chism and Ami Willett.

- Robert Johnson helped with the symposium and the proceedings.

- Paul K. Kuroda and The Foundation for Chemical Research, Inc., provided financial and moral support, as did Bill Casey, Chair of the Geochemistry Division of ACS and Lester Morss, Chair of the Nuclear Chemistry Division of ACS. Madalyn A. Hardy and others at ACS Headquarters helped with publicity.

- Ouyang Ziyuan of the Guiyang Institute of Geochemistry, Li Xibin of the Beijing Astronomical Observatory, and other scientists around the globe were unable to attend the symposium despite great effort.

- Special friends, former and current students gave generously to the success of this undertaking: R. Ganapathy, Marvin Rowe, Tom Ward, Ron Thompson, Koh Sakamoto, Calvin Alexander, Greg Downing, Golden Hwaung, George K.-Y. Chiou, Jiafu Fang, Vic Becker, Robert Ballad, Tadashi Shimamura, Uli Ott, Li Bin, Jauh T. Lee, Ken Windier, Yixiang Xie, Cara Lietz, and Robert Johnson.

- Susan Safren, served as editor for Kluwer Academic/Plenum Publishers. 


\section{Contents}

Contributors $\quad$ v

Preface and Dedication $\quad$ xi

Acknowledgements $\quad \mathbf{x v}$

$\begin{array}{lll}\text { Contents } & \text { xvii }\end{array}$

PART I: GLENN SEABORG AND THE QUEST FOR SUPERHEAVY ELEMENTS 1

Ghiorso Remembers Seaborg 3 ALBERT GHIORSO

Superheavy Elements at Berkeley: The Culmination of Seaborg's

Career

K.E. GREGORICH AND V. NinOV

The Discovery of Superheavy Elements 107-112 and of the

Deformed Shell at $\mathrm{N}=162$

P. ARMBRUSTER 


\section{PART II: THE NUCLEAR REACTIONS THAT MADE OUR ELEMENTS}

The Decay of ${ }^{19} \mathrm{~N}$

D. W. ANTHONY, D. J. MORRISSEY, P. A. LOFY, P. F. MANTICA, J. I. PRISCIANDARO, M. STEINER, J. M. D'AURIA, AND U. GIESEN

Measuring the Astrophysics Rate of the ${ }^{21} \mathrm{Na}(\mathrm{p}, \gamma)^{22} \mathbf{M g}$ Reaction JOHN M. D'AURIA FOR THE DRAGON COLLABORATION

Production and $\beta$-Decay Half-Lives of Very N-Rich Nuclei MONIQUE BERNAS

The Role of the $\mathrm{N}=28$ and $\mathrm{N}=40$ Closed Shells in the Production of the Neutron-Rich Ca-Ti-Cr-Fe-Ni Elements in the Universe O. SORLIN

K. WISSHAK, F. VOSS, C. ARLANDINI, AND F. KÄPPELER

Neutron Capture Cross Section Measurements for the Analysis of the s-Process

ROBERT S. RUNDBERG, J. L. ULLMANN, J. B. WILHELMY, M. M. Fowler, R. C. HAiGHT, G. G. Miller, P. D. PALMER, F. KÄPPELER AND P. KOEHLER

About the Reliability of Extrapolation of Nuclear Structure Data for r-Process Calculations

G. LHERSONNEAU, B. PFEIFFER, AND K.-L. KRATZ

The Astrophysical r-Process

K.-L. KRATZ, P. MÖLLER, B. PFEIFFER, AND F.-K. THIELEMANN

Nuclear Aspects of Stellar and Explosive Nucleosynthesis

THOMAS RAUSCHER, FRIEDRICH-KARL THIELEMANN,

ROBERT D. HOFFMAN, AND STANFORD E. WOOSLEY

Proton Captures in the Atmosphere of Accreting Neutron Stars

H. SCHATZ, L. Bildsten, A. CUMming, AND M. WiesCheR 
PART III: A COSMOLOGICAL VIEW OF NUCLEOSYNTHESIS

The Origin of the Elements

G. BURBIDGE

Chemical Evolution Tomorrow

VIRGINIA TRIMBLE

LiBeB Nucleosynthesis and Clues to the Chemical Evolution of the Universe

V. E. VIOLA

Measurement of the ${ }^{44} \mathrm{Ti}$ Half-life and its Significance for

Supernovae

I. AHMAD, J. P. GREENE, W. KUTSCHERA, AND M. PAUL

On the Half-Life of ${ }^{44} \mathrm{Ti}$ in Young Supernova Remnants

ERIC B. NORMAN AND EDGARDO BROWNE

Abundances in SN 1987A and other Supernovae

ROGER A. CHEVALIER

The Birth of Planetary Systems Directly from Supernovae

WILBUR K. BROWN

Bipolar Outflows in Stellar Astrophysics

ADAM FRANK

PART IV: NUCLIDES IN THE SUN

Mini-blackhole at the Solar Center and Isotopic Abundances in the Primitive Solar Nebula

S. RAMADURAI

Abundances of the Elements in the Sun

N. GREVESSE AND A. J. SAUVAL

Isotopic Ratios: The Key to Elemental Abundances and Nuclear Reactions in the Sun

O. MANUEL 
Critical Evaluation of CI Chondrites as the Solar System Standard of Elemental Abundances

M. EBIHARA, K. SHINOTSUKA, H. OZAKI, AND Y. OURA

Sensitivity of Solar Oscillation Frequencies to Element Abundances 301 JOYCE A. GUZIK AND CORINNE NEUFORGE

Inverse and Forward Helioseismology: Understanding the Interior

Composition and Structure of the Present Sun

CARL A. ROUSE

Heterogeneous Accretion of the Sun and the Inner Planets

GOLDEN HWAUNG

Interstellar Matter, Sun, and the Solar System

M. N. VAHIA AND D. LAL

PART V: NUCLIDES IN THE SUN'S PLANETARY SYSTEM

Isotope Anomalies in Tellurium in Interstellar Diamonds

R. MAAS, R. D. LOSS, K. J. R. ROSMAN, J. R. DE LAETER,

U. OTT, R.S. LEWIS, G. R. HUSS, E. ANDERS, AND

G. W. LUGMAIR

Isotope Abundance Anomalies in Meteorites: Clues to Yields of

Individual Nucleosynthesis Processes

ULRICH OTT

Variation of Molybdenum Isotopic Composition in Iron Meteorites 385 QI LU AND AKIMASA MASUDA

Iron Meteorites and Paradigm Shifts

E. CALVIN ALEXANDER, JR.

Chronology of Early Solar System Events: Dating with Short-lived

Nuclides

JITENDRA NATH GOSWAMI

Xenology, FUN Anomalies and the Plutonium-244 Story

P. K. KURODA AND W. A. MYERS

Extinct ${ }^{244}$ Pu: Chronology of Early Solar System Formation

MARVIN W. ROWE 
A Search for Natural Pu-244 in Deep-Sea Sediment: Progress Report 511

K. SAKAMOTO, Y. HASHIMOTO AND T. NAKANISHI

Strange Xenon Isotope Ratios in Jupiter

K. WINDLER

Abundances of Hydrogen and Helium Isotopes in Jupiter

ADAM NOLTE AND CARA LIETZ

The Possible Role of PeP Weak Interactions in the Early History of the Earth

THOMAS E. WARD

Ce-Nd-Sr Isotope Systematics of Eucrites and Lunar Rocks MASAHARU TANIMIZU AND TSUYOSHI TANAKA

PART VI: THE ORIGIN OF THE SOLAR SYSTEM

Abundance of ${ }^{182} \mathbf{H f}$ and the Supernova Model of the Solar System 575 S. RAMADURAI

Binary Origin of Solar System M. N. VAHIA

Origin of Elements in the Solar System

O. MANUEL 


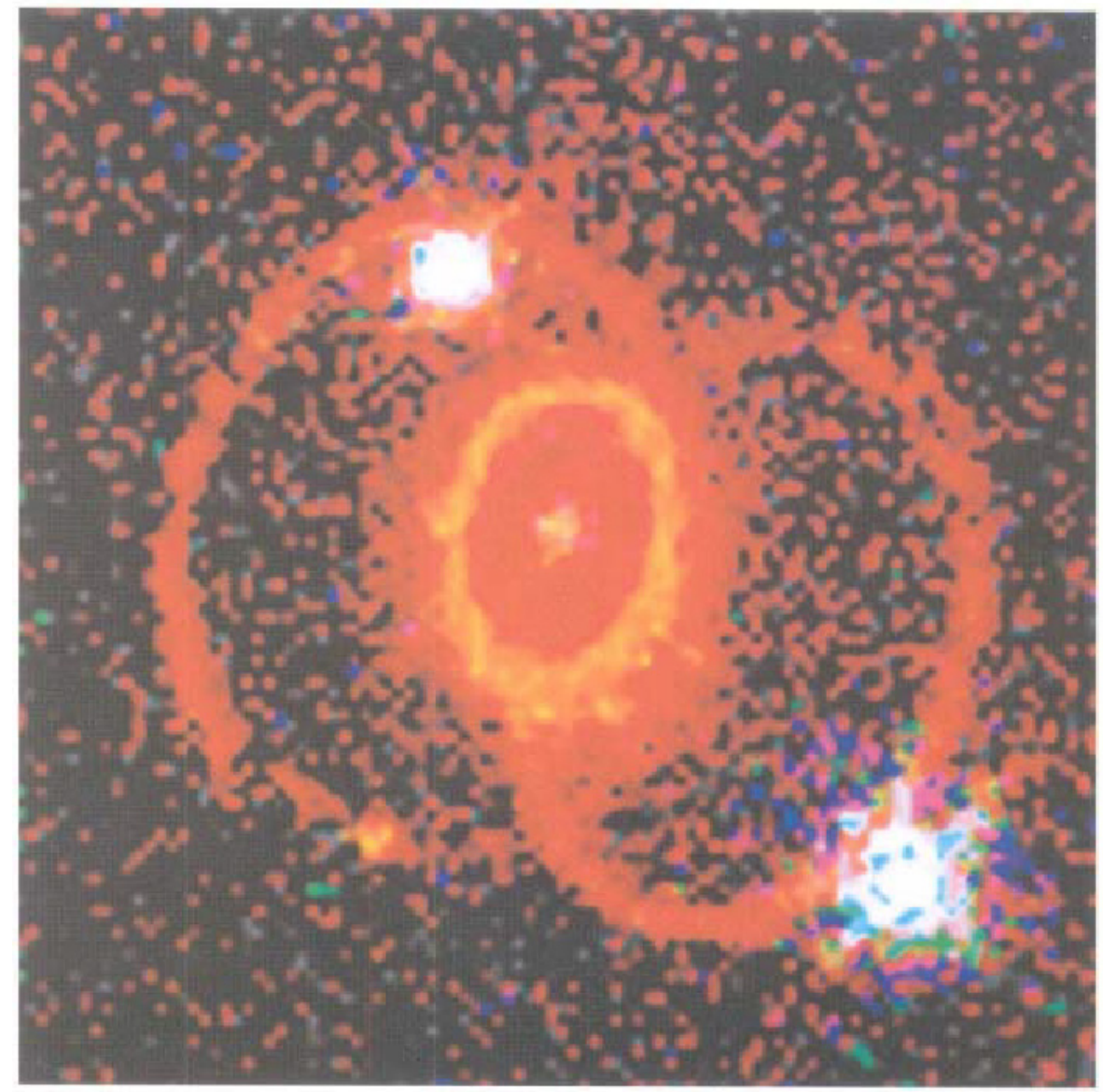

Supernova 1987A is a recent example of one of the stellar nucleosynthesis events that generated many of the nuclides in our solar system. (From NASA). 


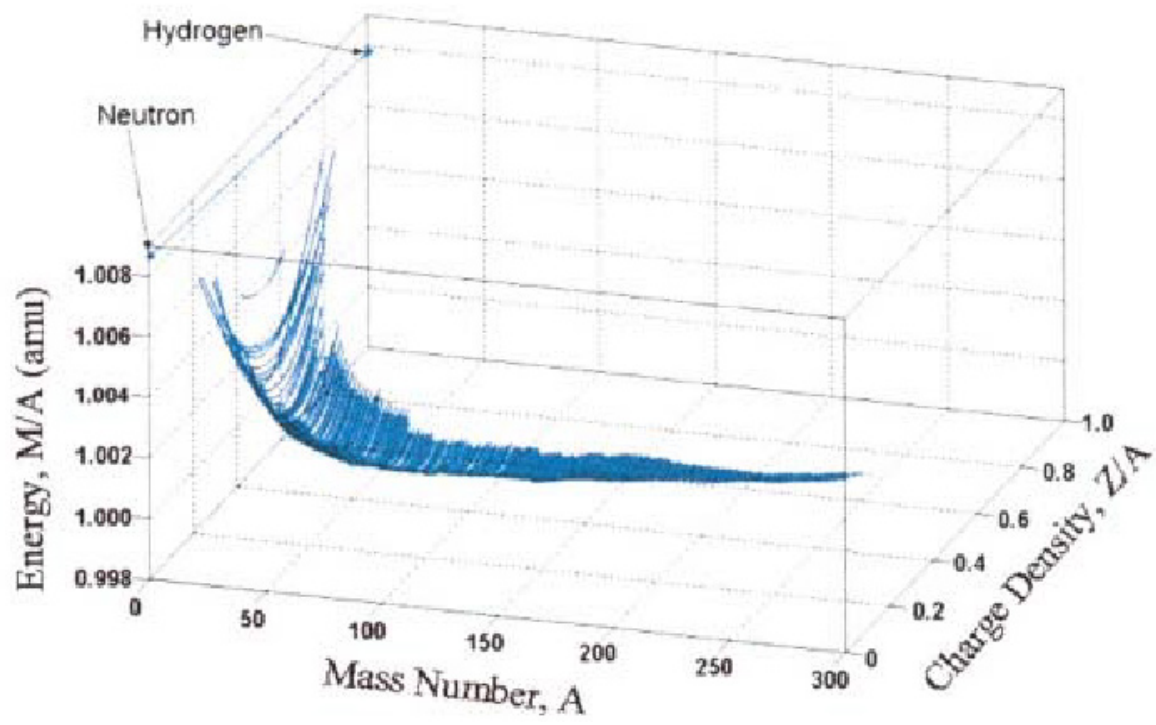

The cradle of the nuclides holds the products of nucleosynthesis. The more stable nuclides lie in the valley, those that are radioactive or readily consumed by fusion or fission occupy higher positions in the cradle. (From FCR, Inc.) 